\title{
Artigos
}

\section{Sociologia da Infância, Protagonismo Infantil e Cultura de Pares: um mapeamento da produção acadêmica sobre o tema}

\begin{abstract}
Resumo: O objetivo deste trabalho foi conhecer, no campo da Sociologia da Infância, como se têm compreendido os conceitos de "culturade pares" e "protagonismo infantil". Procurou-se entender quais os caminhos que estão sendo seguidos para apreender: 1) a criança como ator social e 2) o modo como elas têm se desenvolvido como construtoras de culturas próprias e protagonistas de suas vidas. Para isso,utilizouse a pesquisa bibliográfica de autores estrangeiros e brasileiros que dialogam com 0 assunto, tendo também no Scielo uma importante fonte de dados. Analisaram-se dados de pesquisas e artigos publicados no período de 1994 a 2016 e compreendeuse que cultura de pares é um conjunto de atividades, rotinas, valores produzidos por um grupo de crianças a partir da interação e da brincadeira, e que o protagonismo infantil só é possível a partir das relações de poderes que se estabelecem entre adultos e crianças. Essa relação pode promover ou dificultar a participação das crianças. Os dados obtidos revelam que é preciso mudar a concepção de adulto como superior e da criança como inferior, e criar espaços onde as crianças possam fazer parte das tomadas de decisões dentro do coletivo.
\end{abstract}

Palavras-chave: Sociologia da Infância. Cultura de Pares. Cultura Infantil. Protagonismo Infantil. Participação Infantil.

\section{Sociology of childhood, children participation and peer culture: mapping academic production on the theme}

\begin{abstract}
The main reason for this work was understand in Sociology of childhood, how the concepts of peer culture and children participation have been understood. We seek to understand which ways have been followed to understand the child as a social actor and the way they have been developing themselves as builders of their own culture and participating in their own life. For that it was used bibliographic research of foreign and Brazilian authors that talk about the subject and also having the website Scielo as an important data source. We analyse data and articles published between 1994 and 2016 and we understand that peer culture is a series of activity, routine, values produced by a group of children in interaction of other children and playing together, and children participation is only possible when relations between adults and children are set, able to promote or make it harder the children's participation. The highlight from the data source and analysed articles is that we need to change the conception of the adult as a superior and the child the inferior. It is also important that we create spaces where children can be part of decisions made in group.
\end{abstract}

Keywords: Sociology of childhood. Peer culture. Children participation. Child. Child culture.

\footnotetext{
1 Graduada em Pedagogia pela Universidade Estadual de Campinas. E-mail: flaviafdip@gmail.com 2 Doutora em Educação pela Universidade Federal de São Carlos. Professora da Faculdade de Educação da Universidade Estadual de Campinas. E-mail: gabigt@g.unicamp.br
} 
Sociologia da Infância é um campo de conhecimento que tem se fortalecido no Brasil desde o
início dos anos 2000. Ainda que trabalhos produzidos desde o início do século passado por
autores como Florestan Fernandes (1942) e Marcel Mauss (1937) possam ser indicados como pioneiros no campo, a década de 1980 tem sido frequentemente reivindicada como um marco do desenvolvimento do campo em contexto internacional. A “crise dos paradigmas" vivida pela Sociologia da Educação nos anos 1990 também contribuiu para o desenvolvimento da Sociologia da Infância, como aponta Marchi (2010).

Destaca-se que, em um primeiro momento, as produções do campo da Sociologia da Infância visavam desconstruir o discurso sobre a criança como um objeto passivo dos processos de socialização e uma categoria analítica secundária nos estudos sobre educação, família, etc. e afirmar um novo lugar para as crianças nas pesquisas sociais. De acordo com Marchi (2010, p.183), dentre as principais marcas da Sociologia da Infância, podemos identificar "o princípio da construção social da infância, o da criança-ator e a reivindicação da autonomia conceitual da infância (ou a 'cidadania epistemológica da criança')".

A compreensão da criança como um ator social foi ainda desenvolvida a partir da defesa de que a criança é detentora de um certo "protagonismo", ideia muitas vezes associada à noção de que a criança produz cultura de pares/culturas infantis.

Este trabalho busca discutir o que se compreende por protagonismo infantil e por cultura de pares, a partir do diálogo com a perspectiva da Sociologia da Infância.

Para atingir tal objetivo, realizamos uma pesquisa bibliográfica, a partir do levantamento de referências teóricas publicadas na plataforma Scielo. A análise teve caráter qualitativo e buscou evidenciar o modo como o protagonismo infantil e as culturas infantis têm sido abordados nas produções científicas.

A escolha da plataforma se deu pelo fato de ser necessário realizar um recorte e por assumir que esta plataforma de buscas reúne uma parcela significativa de publicações acadêmicas de qualidade. A definição da plataforma a ser pesquisada também levou em consideração as ferramentas de busca de artigos que o Scielo oferece. Assumimos, assim, que este mapeamento é um primeiro passo e, com isso, desejamos instigar outros pesquisadores a identificar se há diferença significativa dos nossos resultados em relação a outras bases de dados. A fim de contribuir para melhor compreensão sobre o que tem sido escrito em artigos sobre Sociologia da Infância, protagonismo infantil e cultura de pares, realizamos também uma etapa de análise quantitativa dos dados localizados, pela importância de constatar as quantidades de artigos publicados sobre cada tema, além de discutir o que ali tem sido dito.

Uma vez analisados os artigos sobre o tema, entendemos que, na maior parte deles, as crianças são compreendidas como capazes de participar dos processos decisórios, sendo preciso "promover maior aproximação entre crianças e adultos e suas formas de compartilhar projetos, responsabilidades e compromissos" (PIRES; BRANCO, 2007, p. 318). 
Pires e Branco, em artigo publicado em 2007, buscam compreender o significado e as práticas do protagonismo infantil e apontam que, dependendo das relações de poderes que se estabelecem em ambientes escolares, estes podem promover ou apagar por completo a participação das crianças. Nos ambientes em que se encontram adultos e crianças, é possível criar espaços nos quais exista envolvimento delas nos processos decisórios coletivos. Porém o que vemos é que existem práticas sociais bastante consolidadas que não reconhecem as ações das crianças.

A Sociologia da Infância, entendida como um campo de estudo da criança e da infância, tem como alguns de seus principais elementos os conceitos de cultura de pares e o protagonismo infantil, frequentemente mobilizados para explicar a criança como criadora de cultura. Autores como Fernandes $(1942,2004)^{3}$ e Corsaro (2011) discutem as culturas infantis (denominadas por Corsaro como culturas de pares/ culturas de pares infantis) como um conjunto de atividades, rotinas, valores produzidos por um grupo de crianças a partir da interação e da brincadeira. Fernandes, ao estudar as brincadeiras dos grupos infantis que se reuniam para brincar nas ruas do bairro Bom Retiro, evidencia o papel das culturas infantis para a transformação social da Cidade de São Paulo no início do século XX. Corsaro, a partir de seus estudos sobre as crianças em contexto de educação infantil, destaca o papel dos grupos de pares no processo de socialização infantil, como lugar de produção de sentido para o mundo e partilha de preocupações, medos e conflitos. Para ele, é nos grupos de pares, ao ter que lidar com as situações da vida, que as culturas de pares infantis são produzidas, tal como apresentado por ele no esquema transcrito a seguir (Figura 1) e que ilustra o modelo interpretativo de socialização.

Figura 1: O Modelo Interpretativo de Socialização segundo Willian Corsaro

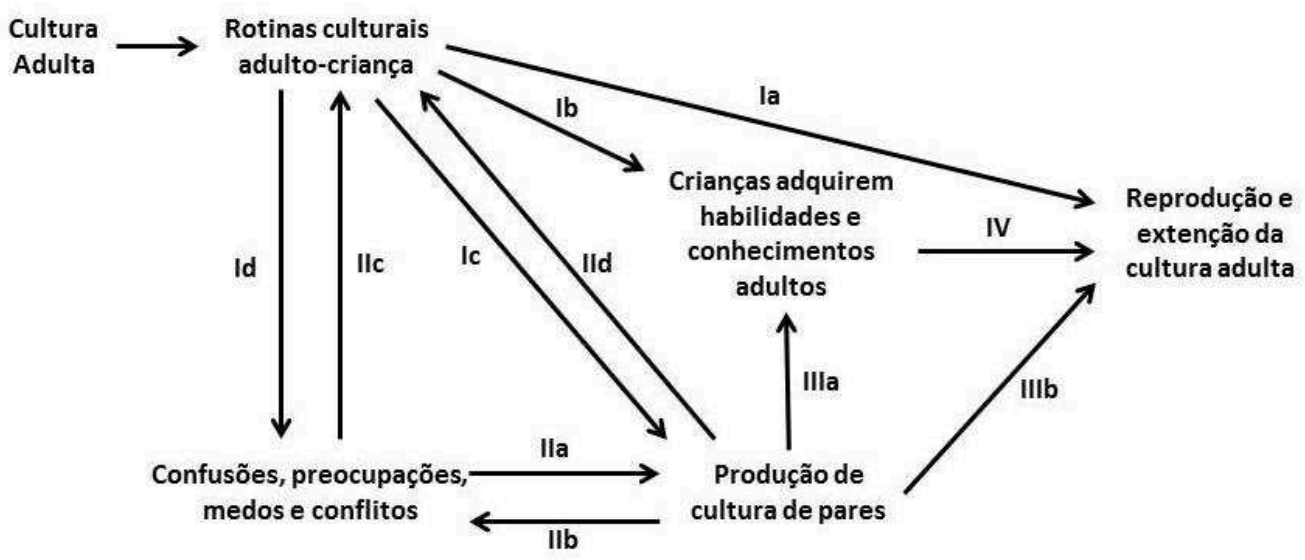

Um modelo Interpretativo da Socialização (Corsaro, 1992, p. 170- livre trad.)

Fonte: Tebet (2013)

Nesse mesmo sentido, é possível argumentar que o brincar é a expressão do protagonismo infantil (QUINTEIRO, 2002) e é o meio que permite às crianças expressar e resolver suas confusões, preocupações, medos e conflitos, assim como criar formas peculiares de interpretar o mundo, o que

\footnotetext{
${ }^{3}$ As trocinhas do Bom Retiro. Texto publicado originalmente em 1942 e republicado em 2004 em versão digital e gratuita.
} 
Corsaro $(1993,2002$, 2009) denomina como "Reprodução Interpretativa" - uma das principais marcas das culturas infantis. A Sociologia da Infância aparece em oposição à ideia de passividade das crianças e de sua socialização orientada unicamente por adultos e instituições sociais. A construção da Sociologia da Infância ${ }^{4}$ vem rompercom a visão, ocidental e adultocêntrica de criança, de que elas não são capazes.

\section{Sociologia da Infância}

A partir da pesquisa realizada e dos dados encontrados com a análise dos artigos no Scielo, a Sociologia da Infância pode ser considerada um campo de investigação recente, e no Brasil ganhou força nos últimos 30 anos. Até o fim do século XX, a infância não tinha um espaço próprio de estudo, e o que existia estava geralmente relacionado à Sociologia da Família e à Sociologia da Educação. As tradicionais teorias de socialização existentes foram reflexo de um momento histórico longo, em que as crianças foram não só ignoradas, como também marginalizadas. Vistas como futuros cidadãos que ocupariam um lugar e trariam contribuições ao mundo adulto, as crianças não eram consideradas indivíduos com interesses específicos ou produtoras de cultura. Apenas internalizavam e reproduziam uma cultura adulta já existente, a chamada socialização, que por muito tempo teve Emile Durkheim como precursor teórico e cujas perspectivas foram significativamente criticadas pelos pioneiros do campo que hoje se denomina Sociologia da Infância.

Pela concepção determinista de Durkheim, "a socialização é um processo de inculcação de valores e saberes pela família, escola e outras instituições, complementada pela influência mais ou menos difusa de elementos do meio ambiente natural e social” (BELLONI, 2007, p. 61). Para Durkheim, o objetivo da socialização é a manutenção do consenso, "entendido como uma comunidade de ideias, crenças religiosas, tradições nacionais ou profissionais, opiniões coletivas, normas e regras aceitas por todos os membros da sociedade" (BELLONI, 2007, p. 64), que possibilita a vida social. Nas palavras do próprio Durkheim (1978, p. 41), "a educação é a ação exercida, pelas gerações adultas, sobre as gerações que não se encontram preparadas para a vida social".

A concepção de socialização que pretendemos analisar aqui difere essencialmente da socialização durkheimiana e leva "em conta a criança como sujeito social, que participa de sua própria socialização, assim como da reprodução e da transformação da sociedade" (MOLLO-BOUVIER, 2005, p. 393). Portanto, a Sociologia da Infância, proposta por alguns autores contemporâneos, se destaca como aquela que vê as crianças como atores sociais que produzem cultura e possuem um papel ativo na sua própria

4 Os trabalhos que têm sido indicados como pioneiros e marcos da constituição desse campo de estudo são: Fernandes, 1945 (no Brasil); Marcel Mauss, 1937 (publicado em português em 2010); Opie e Opie, 1951; Jenks, 1982 (publicado em português em 2002); Qvortrup, 1993 (publicado em português em 2011) e outros. Florestan Fernandes, por exemplo, em seu trabalho "As Trocinhas do Bom Retiro", traz que os grupos infantis estão intimamente relacionados ao desejo de brincar. O que o autor mostra é que as brincadeiras são as causas e os motivos desses agrupamentos. O autor também refuta a ideia de criança como ser passivo e reflexo dos atos dos adultos, pontos que veremos adiante nesta pesquisa como essenciais para o entendimento de conceitos como cultura de pares e protagonismo infantil. 
socialização, bem como na socialização de seus pares. As crianças passaram a ser vistas como protagonistas.

\section{Uma perspectiva histórica}

O historiador Philippe Ariès foi considerado um dos pioneiros no estudo da infância, com seu livro História social da criança e da família. Sua importância para a Sociologia da Infância reside no seu olhar para o caráter histórico e social das crianças. Ele argumenta que o ser biológico criança sempre existiu, mas a categoria social infância, não. No entanto, alguns autores criticaram seu trabalho pela generalização e pelo exagero na ideia de inexistência do sentimento de infância na Idade Média. Segundo ele, na transição do século XVII para o século XVIII, enfatizou-se a ideia da criança frágil e ingênua, e assim, consequentemente, iniciaram-se as práticas de paparicar as crianças.

No século XVII ficou evidente o reconhecimento da infância e da adolescência, pois o crescimento demográfico, as concentrações em áreas urbanas e o papel crucial da escola surgiram então como fatores importantes para esse reconhecimento. Sem contar textos literários, jornalísticos, médicos e também retratos artísticos, que mostram a preocupação com a criança.

O século XIX colocou as crianças e o cuidado com sua vida sob a preocupação da Medicina e da Psicologia. A higiene, o cuidado, a normatização e a prescrição do desenvolvimento a partir das idades, fazem com que as crianças cresçam, tendo o adulto como controlador da infância. Por mais que a Psicologia se mostre uma área do conhecimento que se volta para a criança, seu envolvimento estava mais relacionado com o desenvolvimento e a progressão da criança como indivíduo do que com a ideia de construção da infância.

Os estudos das crianças por muito tempo estiveram ligados diretamente à família ou à escola, e sua socialização vinculava-se à instrução de valores da sociedade adulta, o que as levou ao silêncio e a uma posição marginalizada e passiva diante do mundo adulto, ainda que algumas teorias da Psicologia do Desenvolvimento (como as de Piaget e Vygotsky) já apontassem para a importância de um papel mais ativo da criança na produção de conhecimento.

A Sociologia da Infância constituiu-se sobretudo a partir das décadas de 1980 e 19905 e aconteceu junto com uma série de mudanças na sociedade contemporânea, entre elas as diferentes formas de vida familiar, o consumo diversificado, as alterações na participação no mercado de trabalho, o emprego e a economia global. Fato é que tais mudanças mostraram que a ideia de infância já não era condizente com as necessidades da sociedade. Prout (2010) revela que estava ocorrendo, e ainda ocorre, uma mudança no caráter da infância: as famílias já não vivem mais em um padrão estereotipado. Estudos mostram que as

\footnotetext{
${ }^{5}$ Não há consenso sobre o nascimento da Sociologia da Infância. Marcel Mauss possui um texto sobre a Sociologia da Infância que permaneceu sem publicação por décadas, mas havia sido escrito na década de 1930. Florestan Fernandes, no Brasil, realizou suas primeiras pesquisas sociológicas sobre as crianças e o folclore infantil na década de 1940. Na Europa, a Sociologia da Infância ganhou força a partir dos anos 1980, mas as publicações da época também fazem referência a pesquisas anteriores. De todo modo, é possível que o desenvolvimento da Sociologia da Infância na década de 1980 e 1990, no contexto europeu, esteja associado à ratificação da Convenção Internacional dos Direitos das crianças em 1989, que legitima a participação como direito das crianças.
} 
estruturas familiares sofreram mudanças significativas ao longo dos anos, visto que passaram de famílias substancialmente rurais, com pai e mãe trabalhando no campo (século XIX), para famílias urbanas, com pais trabalhando fora de casa e mães trabalhando em casa (fim do século XIX até meados do século XX), e uma crescente quantidade de famílias com pais solteiros, com mãe e pai trabalhando fora de casa (dos anos 1950 até os dias de hoje). Assim, essas situações de diferentes famílias vivendo de diversas formas já não podem mais ser percebidas como um desvio da norma.

Pensando contemporaneamente, Silva, Raitz e Ferreira (2009), que discorrem sobre a Sociologia da Infância no artigo "Desafios da Sociologia da Infância: uma área emergente", mostram que hoje se vivem novos processos socializadores. Os autores acreditam que os tradicionais espaços socializadores, como a escola e a família, se transformaram e não são os únicos que constroem a identidade do sujeito. A escola, a família e outras agências socializadoras se mostram frágeis como referências de normas e valores, o que faz com que a identidade não seja construída apenas pela cultura adulta.

A concepção de criança e infância não é algo novo, mas o olhar que a contemporaneidade deu a ela é relativamente recente. "A infância está em processo de mudança, mas mantém-se como categoria social, com características próprias" (SARMENTO, 1997, p. 7). A infância não é uma mera passagem de tempo para a vida adulta. As crianças são atores sociais com pensamento crítico e reflexivo.

Porém, algumas preocupações surgem, uma vez que este é um estudo recente e em ascensão. Uma delas é a necessidade de compreender as crianças como sujeitos pertencentes à sociedade. Quinteiro (2002) afirma que é preciso que se reflita sobre a lógica dos papéis tradicionais de adulto e criança, assim como sobre as relações desiguais de poder entre eles. A eterna relação do adulto superior à criança faz com que não se tenha conhecimento sobre o mundo das culturas infantis: "A identidade das crianças é também identidade cultural, isto é a capacidade das crianças constituírem culturas não redutíveis totalmente às culturas dos adultos" (SARMENTO, 1997, p. 8).

As crianças são sempre contadas e retratadas por outro, o adulto. Foi essa marginalização que fez com que elas fossem ignoradas por tanto tempo pela Sociologia, e só recentemente surgisse um estudo específico sobre a infância. O que a Sociologia da Infância se dispõe a fazer é abordar conceitualmente as crianças e a infância a partir de outros referenciais, para além do adulto, ou seja, estudar as crianças por elas próprias.

Corsaro (2011) aponta ainda para a transformação da instituição familiar. Segundo ele, as agências tradicionais socializadoras, como a família e a escola, estão passando por crises e ganhando novos significados. As sociedades contemporâneas vivem em situações pluralistas, confrontadas por uma série de valores distintos. As crianças vivem situações diversas em casa, na escola, na mídia, na sociedade e tentam individualmente, ou de forma coletiva, dar sentido ao mundo em que vivem. $\mathrm{O}$ momento atual que vivemos faz emergir a discussão sobre identidade e pluralidade. 


\section{Características da Sociologia da Infância}

Este é um tópico difícil de ser abordado, uma vez que os diversos pesquisadores da área têm ideias e teorias diferentes sobre o que é a Sociologia da Infância. Porém há uma fala comum que os une e que entendemos quando falamos em "Sociologia da Infância".

Primeiramente é importante apontar que a Sociologia da Infância se apresenta como um campo científico internacional que tem se dedicado aos estudos das crianças e da infância. Ela busca o estudo das crianças e de sua condição para além dos papéis desempenhados no interior da escola e da família, tradicionalmente estudados pela Sociologia da Família e pela Sociologia da Educação (Marchi, 2010).

Dentro desta discussão, William Corsaro(2011) traz uma importante contribuição para este campo de conhecimento: propõe ver a infância a partir de uma perspectiva social. A partir do diálogo com Qvortup, afirma que a infância é um período em que as crianças vivem suas vidas, mas elas também são uma parte da estrutura da sociedade, um grupo dentro da estrutura geracional social: “embora seja um período temporário para a criança, é uma categoria estrutural permanente na sociedade" (CORSARO, 2011, p. 42). Essa perspectiva é desenvolvida por Qvortrup em diversos de seus textos (1993, 1995, 1999, 2009, dentre outros).

Ao mesmo tempo que a infância não é algo natural e universal, as crianças, assim como os adultos, também constroem um discurso social e historicamente situado, ou seja, produzem uma cultura local e singular no interior dos seus grupos de pares infantis. Assim, a infância pode ser entendida como uma categoria geracional na estrutura social, no sentido de que é permanente na sociedade, embora a ideia de permanência não signifique que ela seja única e imutável. O que a criança faz, fala, age - ou seja, o modo como ela interpreta o mundo - diz respeito a algo que é presente, contemporâneo. Existe uma cultura das crianças que é exclusivamente delas.

Uma outra característica que tem sido recorrente entre os pesquisadores diz respeito a compreender a infância como uma construção discursiva. Essa ideia se faz presente no pensamento de James, Jenks e Prout (apud TEBET, 2013).

O texto de Jenks (originalmente publicado em 1982), "Constituindo a criança" representa um primeiro passo no movimento de desconstrução dos discursos fundamentados em imagens "présociológicas" da criança. Seu objetivo era desconstruir os discursos da criança selvagem e da criança natural e constituir a criança como um ser social que desempenha um papel ativo na formulação do mundo social; e a infância como uma construção discursiva, intencionalmente elaborada com o objetivo de "apoiar e perpetuar as bases fundamentais e as noções de humanidade, ação, ordem, linguagem e racionalidade de teorias particulares" (JENKS, 2002, p. 214).

Na mesma perspectiva, James e Prout (2007) rejeitam a ideia de que a infância se constitua como um componente natural e universal de todas as sociedades, ligado à imaturidade biológica das crianças, e defendem a compreensão da infância como um discurso social e historicamente situado, variável e relativo, sendo possível identificar,em diferentes contextos sociais ou históricos, distintos discursos e compreensões da infância. 
O que os autores propõem, portanto, é que, ao invés de buscar o que seria a criança ou a infância (algo amplamente difundido e problematizado pelas compreensões biológicas e psicológicas, que tendem a uniformizar e homogeneizar a infância), deve-se analisar como as diferentes práticas produzem diferentes infâncias. Esta também é uma reflexão em comum com as pesquisadoras brasileiras Anete Abramowicz e Fabiana de Oliveira, por exemplo, que compreendem que devem ser levados em consideração para pensar as infâncias os fatores heterogêneos, como: classe social, raça, gênero, religião, tempo, localidade etc., "tendo em vista que os diferentes espaços estruturais diferenciam as crianças" (ABRAMOWICZ; OLIVEIRA, 2010, p. 43).

Outro ponto recorrente entre os autores estudados e que marca a Sociologia da Infância é o termo cultura de pares. De acordo com Giddens:

[...] o conceito de cultura, tal como o de sociedade, é uma das noções mais amplamente usadas em Sociologia. A cultura consiste nos valores de um dado grupo de pessoas, nas normas que seguem e nos bens materiais que criam. [...] A cultura refere-se aos modos de vida dos membros de uma sociedade, ou de grupos dessa sociedade. Inclui a forma como se vestem, os costumes de casamento e de vida familiar, as formas de trabalho, as cerimônias religiosas e as ocupações dos tempos livres. Abrange também os bens que criam e que se tornam portadores de sentido para eles - arcos e flechas, arados, fábricas e máquinas, computadores, livros, habitações (GIDDENS, 2004, p. 46-47).

Para Fernandes $(1942,2004)$, o conceito de cultura é mais amplo que o conceito de folclore, e a cultura infantil inclui natação, futebol e certos trabalhos caseiros, além das cantigas, dos contos e das brincadeiras infantis; ela envolve elementos aceitos da cultura do adulto e elementos elaborados pelas próprias crianças. A expressão "culturas de pares”, em geral, é utilizada na Sociologia da Infância, a partir dos estudos de Corsaro (2011), para se remeter às culturas infantis. O termo pares é utilizado para dizer que esta construção de cultura infantil é feita em conjunto, a partir de um grupo que compartilha momentos juntos e interage presencialmente. A partir deste entendimento de cultura e de pares, William Corsaro (2011, p. 128) define cultura de pares ${ }^{6}$ como "[...] conjunto estável de atividades ou rotinas, artefatos, valores e preocupações que as crianças produzem e compartilham em interação com as demais". Manuel Jacinto Sarmento (2004, p.9), em seu texto "As culturas da infância nas encruzilhadas da segunda modernidade", apresenta a importância da interatividade das crianças para o entendimento de cultura de pares: "Esta aprendizagem é eminentemente interativa; antes de tudo o mais, as crianças aprendem com as outras crianças, nos espaços de partilha comum". Nesse sentido, a infância como construção cultural pode ser compreendida como a elaboração, pelas crianças, de "seus próprios saberes, suas memórias e lembranças, suas práticas e possibilidades de criar e recriar a realidade social na qual se encontram inseridas" (QUINTEIRO, 2002, p. 141).

O que gostaríamos de apontar é a importância da atividade coletiva e o modo como a cultura de pares reinventa e produz cultura. A partir do coletivo, das brincadeiras e dos espaços que favorecem a

\footnotetext{
6 Convém destacar que, no contexto da língua inglesa, a expressão "peer" é utilizada para remeter ao grupo de amigos. Tal conceito, que vem sendo traduzido como "pares', poderia ser igualmente traduzido como "turma" ou "trocinha" (nos termos utilizados por Florestan Fernandes) e não se restringe a um grupo de crianças da mesma idade, do mesmo sexo, raça ou de um mesmo contexto, mas refere-se a um grupo de crianças que se identifica como pertencendo à mesma turma ou grupo de amigos, independente das características desse grupo e do contexto em que se constitui. Todavia, em pesquisas realizadas em contexto escolar, a noção de pares, muitas vezes acaba coincidindo com a noção de turma ou série.
} 
interação entre as crianças, faz-se possível a construção das diferentes infâncias. As crianças não se limitam somente a internalizar os valores da sociedade e da cultura em que estão inseridas, mas contribuem ativamente para a produção e para mudanças culturais - por isso a importância da brincadeira. De acordo com o autor, as culturas de pares infantis são marcadas ainda por processos de transição entre diferentes instituições (como a família, a creche, a escola); por aspectos simbólicos (dentre os quais, a mídia, a literatura e histórias infantis, as figuras míticas e as lendas) e materiais (que incluem vestuário, brinquedos e ferramentas artísticas e escolares); por amizade, desejo de compartilhamento, autonomia e controle, desafio à autoridade adulta; ou, ainda, por conflitos entre as crianças e pela diferenciação social (CORSARO, 2003, 2009, 2011).

É possível, portanto, definir o brincar como uma das formas de expressão principais do protagonismo infantil, sobretudo no âmbito das culturas infantis (CORSARO, 1993, 2002, 2003), ou seja, o exercício da criatividade e a capacidade de produzir. Jucirema Quinteiro (2002), a propósito, afirma que, por meio da brincadeira, a criança é capaz de construir significados para as ações que realiza e, ao mesmo tempo, desenvolve a capacidade de reconhecimento simbólico, tão importante para as atividades culturais.

O interesse das instituições e dos agentes sociais a respeito da forma como ocorrem os processos de socialização das crianças tinha o objetivo de saber como melhor inseri-las na sociedade. A crítica da Sociologia da Infância sobre esse conceito de socialização trouxe a ideia da criança como ator social. Assim, através do brincar, do imaginário e da interação com as demais, as crianças se mostram protagonistas de suas vidas e criadoras de culturas. Portanto, o protagonismo infantil implica a participação das crianças na sociedade e nos processos decisórios. No coletivo, elas conseguem criar, tomar decisões, resolver situações e ser protagonistas da sua própria história. Pires e Branco desenvolvem o entendimento de protagonismo infantil a partir de textos de Qvortrup e Sarmento e afirmam que: “As crianças possuem características próprias ao seu momento desenvolvimental, o que não as torna menos competentes enquanto atores sociais nem seres incompletos ou imperfeitos, mas caracterizam elementos configuradores de um grupo singular na existência humana” (PIRES E BRANCO, 2007, p. 316).

Rompendo com a ideia de sujeitos passivos, que estão no mundo para aderir aos valores da sociedade adulta, a Sociologia da Infância vê a criança como sujeito e ator social do seu processo de socialização e infância. Os pesquisadores desta emergente área acreditam que as crianças são participantes ativos na construção social da infância e de culturas, e que a Sociologia da Infância compreende a criança como sujeito da história, que atribui significados à sua cultura própria e dá sentido a ela.

Pensando em todo o contexto da Sociologia da Infância apresentado até aqui, compreendemos que a criança é sujeito e protagonista da história, e com isso constrói a cultura que vive. Entendemos ainda que a cultura de pares também é nuclear, ou seja, pertence aos pequenos grupos que vivenciam aquela cultura. Corsaro (2011) aponta que as culturas locais produzidas pelas crianças integram culturas mais amplas, de outras crianças e também dos adultos. 


\section{Mapeamento: reflexões a partir dos dados levantados no Scielo}

Este é um importante momento da pesquisa, no qual vamos analisar o que está sendo dito sobre Sociologia da Infância, protagonismo infantil e cultura de pares. $O$ que pesquisadores estão compreendendo e publicando em artigos.

O site escolhido como fonte para levantamento dos artigos escritos foi o scielo.org. Para uma abordagem mais detalhada do assunto, buscamos o trabalho desenvolvido por Dip (2016). A metodologia escolhida para ser utilizada neste trabalho foi a análise de dados a partir de uma pesquisa documental. No trabalho com o site foi usada a forma integrada, pesquisa feita no regional e foram utilizados todos os indices. Foram usadas como descritores as palavras: 1) sociologia da infância; 2) protagonismo infantil; e 3) cultura infantil. A escolha desses descritores foi decorrente da temática abordada neste artigo e da importância de fundamentar a pesquisa feita acima. O recorte dos anos utilizados nesse momento da pesquisa foi o apresentado pelo siteScielo, e não houve nenhuma restrição a priori.

\section{Sociologia da Infância}

A pesquisa começou selecionando no Scielo artigos que abordassem a Sociologia da Infância. Na barra de pesquisa foi colocada a expressão "sociologia infância" em apenas um campo e selecionada a opção buscar em "todos os índices". Resultaram da busca 59 artigos publicados com essas palavras envolvidas. As pesquisas variavam em um curto período de tempo, e a mais antiga data de 1999. O que esse levantamento mostra é que, em um período de 11 anos (1999 a 2009) foram feitas 26 publicações sobre o tema, enquanto, em um período de 7 anos mais recentes (2010 a 2016), foram realizadas 33 pesquisas. O Gráfico 1 expõe esses dados.

Gráfico 1: Quantidade de pesquisas realizadas sobre "Sociologia Infância" nos anos de 1999 a 2016

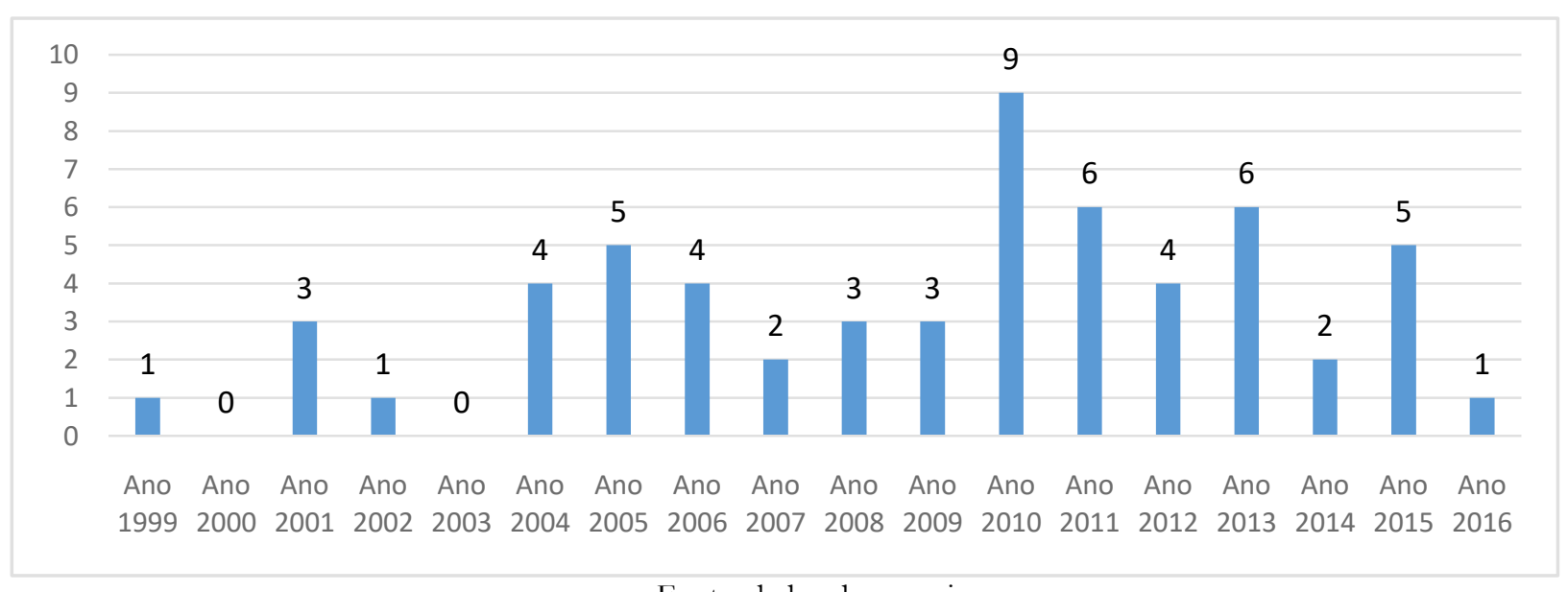

Fonte: dados de pesquisa

Isso mostra como o tema Sociologia da Infância tem ganhado cada vez mais espaço nas produções brasileiras. Importante destacar que a análise destes dados foi feita em abril de 2016. Em razão do grande número de artigos, propusemo-nos a aprofundar nossas análises, observando as palavras-chave, 
que nos indicam um pouco em que caminho estes artigos estão seguindo.Os 59 artigos que apareceram tinham como soma 214 palavras-chave. Vamos analisar as 7 que mais se repetiram nos estudos. O Gráfico 2 assim revela:

Gráfico 2: Palavras-chave encontradas em artigos sobre "Sociologia Infância"

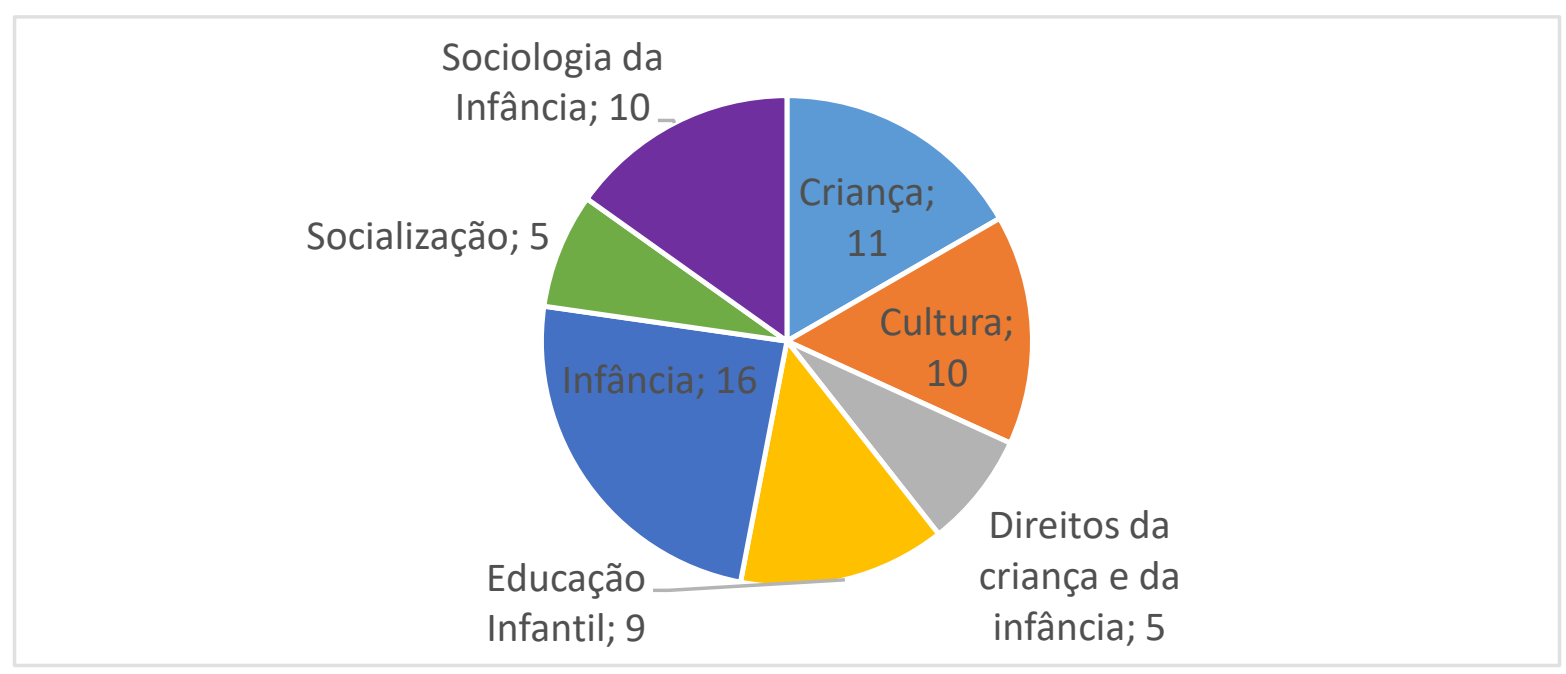

Fonte: Dados de Pesquisa

A partir da análise do gráfico, conseguimos fazer alguns apontamentos:

Primeiramente, as duas palavras-chave com maior número nos artigos são "criança" e "infância", que, juntas, aparecem 27 vezes (não necessariamente em 27 artigos, porque podem ter aparecido repetidas no mesmo artigo), ou seja, seus autores relacionaram Sociologia da Infância com estudo de crianças e sua infância, o que já era esperado, devido ao próprio objeto de estudos da Sociologia da Infância. Interessante que também há uma palavra-chave que apareceu em 5 artigos, relacionada a estas duas palavras: direitos da criança e da infância, o que nos leva a crer que a Sociologia da Infância também tem contribuído para debates no âmbito dos direitos das crianças.

A palavra-chave cultura foi ainda mais expressiva nos artigos localizados a partir do buscador Sociologia da Infância, tendo aparecido em dez pesquisas diferentes. Dessas dez pesquisas, oito estavam intimamente ligadas com a cultura de pares infantis7, as outras duas usavam o termo "cultura" relacionado com o sentido de uma cultura das sociedades, não relacionadas necessariamente com a infância.

Isso se revela bastante coerente com o estudo sobre os pensadores da Sociologia da Infância, uma vez que as crianças se mostram construtoras da sua própria cultura e participantes da cultura adulta também. Tal resultado confirma que o estudo da Sociologia da Infância está intimamente ligado ao das culturas infantis. Importa destacar que esses debates têm se difundido no Brasil, em especial no campo da Educação Infantil, tal como apontam Abramowicz (2015) e Nascimento (2013). Nesse contexto, a noção

${ }^{7}$ Altino José Martins Filho (2009); Ana Cristina Coll Delgado e Fernanda Muller (2005); Bianca Rodriguez Corsi (2011); Eric Plaisance (2004); Flavia Santiago (2015); Marcia Buss-Simão, Francisco E. de Medeiros, Ana Márcia Silva e José J. S. Filho (2010); Patrícia Dias Prado (2013); e Vanessa F. A. Neves, Maria Lúcia Castanheira e Maria Cristina S. Gouvêa (2011). 
de culturas infantis tem sido especialmente mobilizada no âmbito da educação infantil, para subsidiar debates sobre o papel e a importância da brincadeira nessa etapa da educação.

Os termos infância, criança e sociologia da infância já eram esperados nesta busca, por estarem indissociáveis na pesquisa sobre Sociologia da Infância. Todos os artigos em que apareceu o termo socialização estavam relacionados com o estudo da criança e da infância, porém em contextos diferentes. Sebastião (2013) trata dos processos de socialização e da violência na escola; Grigorowitschs (2008) traz uma análise dos processos de socialização na infância, com base em Georg Simmel e George H. Mead; Martins (2008) aborda processos de socialização entre adultos e crianças nas creches; Correia, Giovanetti e Gouvêa (2007) tratam da socialização a partir das vivências da infância no Movimento dos Trabalhadores sem Terra; e Mollo-Bouvier (2005) apresenta a transformação dos modos de socialização das crianças dentro de uma abordagem sociológica.

Por último, mas não menos importante, a palavra-chave educaşão infantil apareceu em nove dos artigos escritos relacionados à Sociologia da Infância, de modo que nossos dados reforçam as afirmações de Abramowicz (2015) e Nascimento (2013). O que é interessante nesta palavra-chave é que o estudo sobre a infância está relacionado em grande parte com as crianças pequenas. Ainda que a infância não se restrinja apenas ao período da educação infantil, é ali que esse debate tem conquistado espaço. Tal dado também evidencia que - ao se desenvolver, especialmente, em contexto escolar - a Sociologia da Infância segue voltada, sobretudo, para a criança na condição de "aluno". Fica evidente, portanto, a necessidade de ampliar nossas pesquisas sobre as vidas das crianças e a infância para além dos muros escolares e de reconhecer a infância das crianças mais velhas ou, mesmo, a infância, para além dos limites etários, estabelecidos cronologicamente.

\section{Protagonismo Infantil}

A pesquisa trouxe apenas 15 resultados com pesquisas de 2001 a 2016. Em um primeiro momento, o que mais chama a atenção nesses artigos encontrados é que eles não estão apenas relacionados com a criança e a infância no campo da Sociologia ou das Ciências Sociais, mas também abordam a área da saúde.

Nove dos trabalhos estavam vinculados a estudos com crianças, mas em suas mais diversas áreas: participação infantil em questões públicas, políticas e sociais; trabalho infantil; construção da identidade e literatura infantil; questões de gênero, entre outros temas. Cinco deles estavam diretamente ligados à área da saúde, com assuntos como: HIV; estudantes de medicina; cuidado humanizado no pré-natal; promoção e educação para a saúde com crianças; e nutrição e risco de obesidade em crianças. E, por último, um artigo ficou entre essas duas áreas de estudo, pois trabalha a violência contra crianças e adolescentes em questões sociais e questões de saúde pública. ${ }^{8}$ Mesmo que, de uma maneira geral os artigos falem sobre

8 Abraham Osorio Ballesteros (2016); Coromoto Macías-Tomei, Marianella H. Hernández, Mariana M. Elizondo e Daniela Useche (2014); Lívia Carvalho de Assis, André da Silva Mello, Amarílio Ferreira Neto, Wagner dos Santos e Omar Schneider (2015); Mari C. Davó, Diana Gil-Golzález, Carmen Vives-Cases, Carlos Álvarez-Dardet e Daniel La Parra (2008); Maria Cecília de Souza Manayo 
crianças, nenhum utiliza o termo "Sociologia da Infância" nas palavras-chave. O Gráfico 3 é ilustrativo dessa distribuição.

Gráfico 3: Áreas relacionadas ao estudo de Protagonismo Infantil

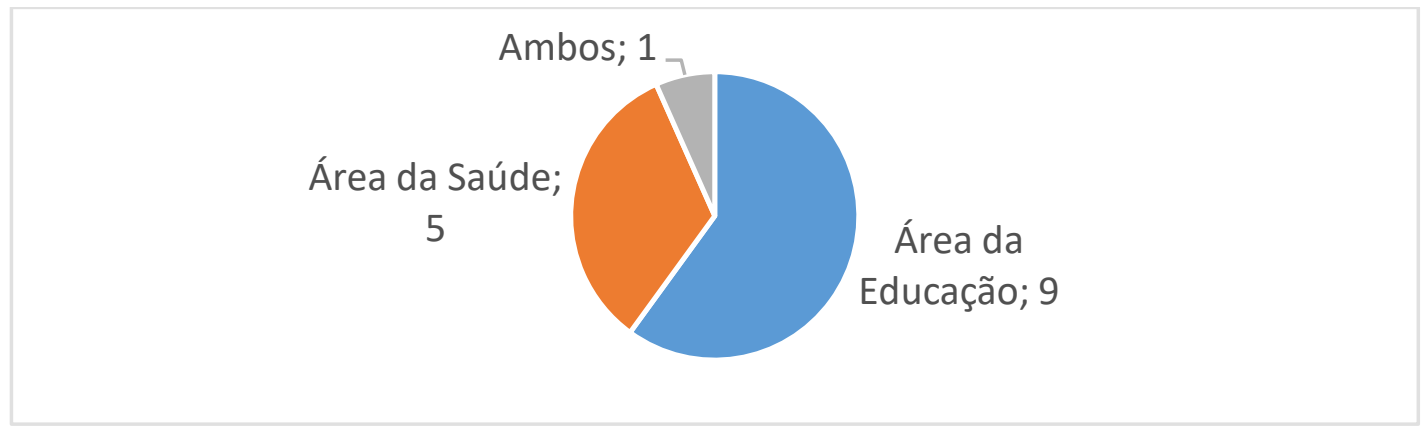

Fonte: Dados de Pesquisa

\section{Cultura de Pares}

A pesquisa a partir do buscador "Cultura de Pares", sem recorte de período/data, nos remeteu a um conjunto de 83 pesquisasrelacionadas a Ciências Agrárias, Ciências da Saúde, Ciências Humanas, Ciências Sociais Aplicadas, Ciências Biológicas, Linguística, Letras e Artes, Engenharias e Ciências Exatas e da Terra. De uma maneira geral, muitas áreas utilizam o termo cultura de pares e muitos dos trabalhos não fazem parte do que procuramos compreender e pesquisar neste estudo.

Portanto, tentamos cultura infantil, que trouxe 154 resultados. Foi muito interessante analisar os dados obtidos com esse termo, primeiro pela quantidade de pesquisas encontradas, significativamente maior do que com os termos protagonismo infantil e sociologia infância. Segundo, porque, pela quantidade de pesquisas, assuntos diversos se apresentaram quando analisamos os dados, além de temas que já haviam sido constatados nas análises anteriores.

Assim como na pesquisa no Scielo com o termo protagonismo infantil, muitas pesquisas com o descritor culturas infantis estavam relacionadas com as áreas da saúde - 33 dos resultados. Tal como ocorreu no caso da análise das publicações sobre sociologia da infância, as pesquisas relacionadas a cultura infantil são recentes e possuem maior incidência a partir de 2009, mas nem sempre os artigos localizados estavam vinculadosao nosso tema de estudo. Um exemplo é a pesquisa de 1994, sobre o estado nutricional de crianças menores de 5 anos em aldeias indígenas. A primeira publicação localizada no Scielo que adota o termo cultura infantil data de 1999, é assinada por Ana Lúcia Goulart de Faria e apresenta a concepção de Mário de Andrade em relação à educação das crianças nos parques infantis`. Entre 1999 e 2008, 49 artigos foram encontrados sobre cultura infantil; e 105 artigos foram encontrados, publicados entre 2009 e 2016.

(2001); Mónica Peña Ochoa (2010); Sarai Miranda Juárez e Daniel Alberto (2015); Sergio F. S. Pires, e Angela Uchoa Branco (2007); Sergio F. S. Pires e Angela Uchoa Branco (2008).

9 Trabalho de Ana Lúcia Goulart de Faria, A contribuição dos parques infantis de Mário de Andrade para a construção de uma pedagogia da Educação Infantil. O artigo fala sobre os parques infantis do Departamento de Cultura da Prefeitura Municipal de São Paulo, na gestão Mário de Andrade. A partir da experiência educacional com o folclore e a diversidade étnica brasileira, os filhos da família operária da época tinham o direito à infância garantido através das artes e dos jogos tradicionais infantis. Segundo o texto, os parques infantis promoviam "o direito à infância, isto é, com o direito ao não-trabalho, com o direito de brincar e de criar a cultura infantil, permanecendo crianças pelo menos enquanto estivessem no parque" (FARIA, 1999, p.70). 
Outro gráfico (Gráfico 4) importante sobre as palavras-chave encontradas nos ajuda a entender o que essas pesquisas estão dizendo.

Gráfico 4: Palavras-chave mais recorrentes em pesquisas sobre Cultura Infantil

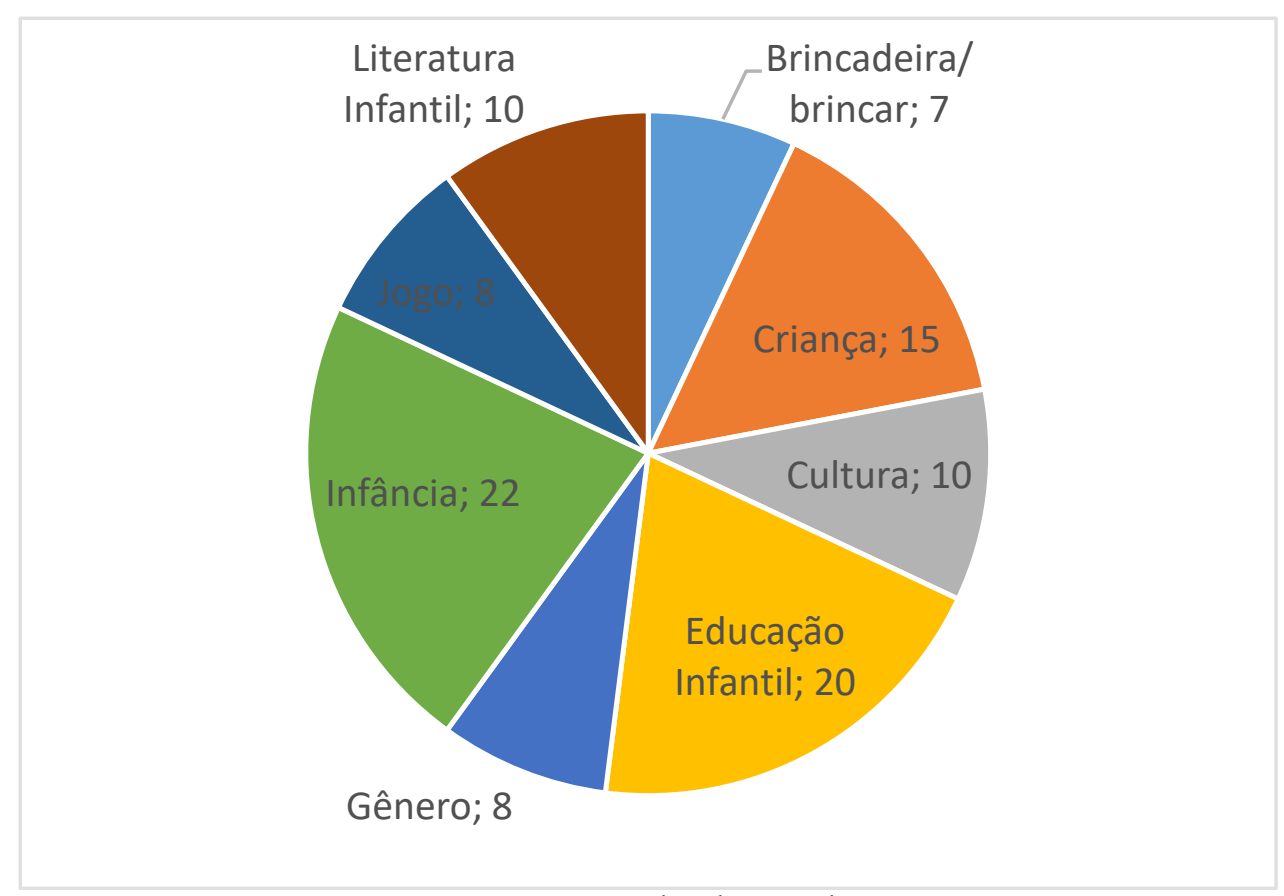

Fonte: Dados de Pesquisa

Assim como na pesquisa realizada sobre sociologia da infância, os termos criança e infância apareceram com frequência, mais especificamente, 37 vezes.

Nossa análise permitiu concluir que tais palavras apareceram devido ao caráter e ao objeto de estudo sobre culturas infantis. Assim também, a palavra cultura, que já aparece no termo pesquisado, era esperada. Os termos que não derivam diretamente das palavras utilizadas na busca e que mais apareceram foram: brincadeira/brincar; gênero, jogo e literatura infantil.

Foi muito significativo encontrar os termos brincadeira/brincar, jogo e literatura infantil em 25 pesquisas. Eles são elementos próprios do universo da criança. Utilizando as ideias aqui referidas de autores como Quinteiro e Corsaro, que compreendem que o cotidiano, a rotina e a convivência entre crianças trazem consigo as marcas de sua cultura, podemos inferir que os momentos de brincadeira, jogo e leitura são fundamentais para a construção da infância. Abramowicz e Oliveira (2010) apontam que tais momentos não são aqueles colocados pela Pedagogia como "estratégia de aprendizagem", e sim aqueles em que as crianças criam, imaginam, se expressam através da brincadeira espontânea - em que se revelam vivamente o protagonismo infantil e a cultura de pares.

As pesquisas que tinham esses termos como palavras-chave estavam relacionadas a corpo, a Educação Física, linguagem corporal, imaginário, lúdico, corpo brincante, meios de comunicação, universo infantil, diversidade, valores, contexto escolar, movimento, desenvolvimento infantil, relações, transmissão cultural, entre outros temas. 
Sendo a escola o espaço onde as crianças passam grande parte de seu tempo, muitas vezes essa cultura infantil é construída a partir das experiências ali vividas por elas. É também o espaço onde o sujeito se torna social, ou seja, deixa de ser exclusivamente familiar, passa a interagir com um mundo diferente do da casa. Ali as crianças convivem com diferentes vidas, jeitos de ser e pensar, entram em contato com culturas diversas. Assim, chegamos ao termo Educação Infantil, o segundo que mais apareceu nas pesquisas sobre cultura infantil (20 vezes), mostrando que o espaço para encontro diário e frequente de um grupo de crianças é fundamental para que, juntas, possam simbolizar, interpretar e construir suas compreensões sobre o mundo, suas culturas infantis/ culturas de pares.

Cabe ressaltar, no que diz respeito aos artigos que abordavam brincadeira e jogo, que uma das principais referências brasileiras sobre a temática hoje é, sem dúvida, a pesquisadora Tizuko Kishimoto, citada em boa parte dos artigos localizados. A trajetória da pesquisadora é marcada por uma aproximação com a Sociologia do Jogo, de Jacques Henriot, mas o campo de conhecimento que mais se sobressai nas publicações da autora é a antropologia (com forte influência de Gilles Brougère), na interface com educação e cultura. A própria Kishimoto, ao ser indagada sobre sua relação com a Sociologia da Infância, afirma que em sua trajetória acabou fazendo outras escolhas. ${ }^{10}$

Outro termo muito significativo aponta uma discussão que ainda não tinha aparecido na pesquisa realizada no site Scielo: gênero, tema que aparece em oito pesquisasque abordam relações gênero em diversos momentos da vida infantil. Elas procuram entender a mídia, programas de TV, teatros, clubinhos infantis, ou seja, espaços que fazem parte da cultura infantil e estão repletos de estereótipos de gêneros.

De modo geral, o termo cultura infantil está relacionado com as experiências vividas pelas crianças no coletivo a partir de jogos, brincadeiras, leituras, preocupações, rotinas, entre outros momentos, e, portanto, ele se relaciona com a Sociologia da Infância no momento em que esta faz uma releitura da cultura infantil e entende a criança como ator social com papel importante nas práticas sociais e culturais e na socialização de seus pares.

\section{Interfaces entre sociologia da infância, protagonismo infantil e cultura de pares}

Esta pesquisa se preocupou em entender melhor estes três temas: Sociologia da Infância, protagonismo infantil e cultura de pares, e procurou estabelecer uma ligação entre eles. Após muito estudo, leitura e análise de dados, é possível estabelecer uma linha que une essas três percepções da infância.

O estudo da Sociologia da Infância abarca conceitos de protagonismo infantil e cultura de pares, uma vez que são dois exemplos de participação da criança na sociedade. O que a Sociologia da Infância

\footnotetext{
10 De acordo com entrevista presente no CD-room que integra o livro Estudos da Infância no Brasil (ABRAMOWICZ, 2015), ao ser questionada em relação à Sociologia da Infância, Kishimoto responde:

"Olha, na verdade quem mexe com antropologia também se aproxima da Sociologia. Com o Gilles eu aprendi muito de Sociologia, mas não dá para eu atuar em todos os campos. Não dá para eu atuar em todos os campos, porque eu teria que pegar uma literatura e... Focar algumas pesquisas, então, nessa minha carreira, eu peguei um pouco da cultura, entrei mesmo nas teorias da antropologia e peguei mais o viés da profissionalização da educação infantil e das práticas".
} 
procura mostrar é que a criança é construtora de cultura e é capaz de interferir na cultura adulta também, como afirma William Corsaro (2011), Fernandes (2004), dentre outros. A partir de brincadeiras, jogos imaginários, preocupações do grupo, conflitos, quer na rotina, quer em outros momentos especiais, as crianças criam uma cultura que pertence a elas. Coletivamente, elas conseguem criar, tomar decisões, resolver situações e ser protagonistas da sua própria história.

Porém, para compreender esta ideia de criança como ator social, é necessário mudar a visão de adulto e criança, e isto é posto pela Sociologia da Infância, tanto nos estudos sobre cultura infantil, como naqueles sobre participação infantil. Autores como Pires e Branco (2007) e Quinteiro (2002) mostram que é necessário desconstruir o abismo que existe entre a criança e o adulto, e que as crianças não são seres rasos que necessitem ser preenchidos com o conhecimento adulto. Elas possuem conhecimentos e percepções, e há construção de conhecimento no mundo infantil.

Importa, porém, ter claro que adultos e crianças assumem responsabilidades diferentes, ou seja, as preocupações infantis não são do mesmo caráter que as do adulto. Portanto, é necessário frisar que a divisão do "mundo entre crianças e adultos, não facilita este tipo de configuração e compartilhamento de responsabilidade e compromissos" (PIRES; BRANCO, 2007, p. 317).

E por que é tão difícil para o adulto compreender a participação da criança no mundo? Abramowicz e Oliveira (2010, p.44) apontam que "por vezes o cardápio de sentidos que dispomos é insuficiente para compreender estas falas. A criança é portadora da diferença, da diversidade e da alteridade”. É preciso que as sociedades valorizem as capacidades das crianças. É preciso superar a ideia de sua incapacidade, para que a participação infantil seja aceita como uma realidade social.

Portanto, as ideias da Sociologia da Infância, sobre o protagonismo infantil e a cultura de pares exigem uma mudança de pensamento em relação à criança e à infância. É preciso propiciar que os espaços que as crianças frequentam permitam sua participação e criação. Por vezes, isso não acontece porque não temos o hábito de perguntar, nem, muito menos, de ouvi-las. É preciso ouvir as crianças, mas o que o mundo faz é abafar cada vez mais sua voz, deixando-as silenciadas e sem poder de participação. Ainda assim, as crianças criam suas estratégias e buscam seu espaço. Criam, e participam, mesmo quando não possuem autorização para tal.

\section{Considerações finais}

Este trabalho trouxe muitas reflexões sobre o estudo da criança e da infância. Desde a perspectiva histórica até o que hoje está sendo estudado sobre a Sociologia da Infância. As análises dos dados recolhidos nos artigos encontrados no Scielo mostram como é recente a consolidação da Sociologia da Infância e seus debates sobre cultura infantil e protagonismo. No Brasil, apesar do estudo de Fernandes (1942, 2004) sobre folclore e cultura infantil ter sido produzido na década de 1940 somente em 1990 novos trabalhos sobre infância e cultura, com perspectiva sociológica começaram a surgir e vêm crescendo até os dias de hoje. Assim, é possível concluir que ainda é preciso elaborar mais pesquisas sobre os temas. 
Inclusive porque, analisando a proposta deste trabalho, que foi buscar o que se tem produzido sobre a Sociologia da Infância e a relação entre os temas cultura de pares e protagonismo infantil, percebemos que muito já se avançou no seu estudo, mas eles ainda não estão esgotados. Mapeamos aqui as produções sobre cultura infantil e protagonismo infantil no campo da Sociologia da Infância. Uma pesquisa similar sobre o modo como no Brasil nos temos apropriado do conceito inglês "agency" poderia somar-se aos debates que traçamos aqui.

Do mesmo modo, o campo poderia se beneficiar de pesquisas que se debruçassem sobre os coletivos de bebês. Seria possível afirmar, a partir dos conceitos que a Sociologia da Infância tem desenvolvido, que os bebês configuram grupos de pares ${ }^{11}$ ? Seriam os conceitos cultura infantil/ culturas infantis pertinentes para o seu estudo? De que modo a noção de geração impacta na produção de culturas de pares entre crianças que se aproximam da adolescência? Existiriam culturas infantis que atravessem os adultos? Qual a pertinência e a diferença de discutir culturas infantis, no plural, como propõem Sarmento (1997) e Cohn (2005), e cultura infantil, no singular, tal como utilizada por Fernandes (2004)? Essas são algumas perguntas que ainda carecem de novas investigações. Certamente se faz necessário ampliar os estudos sobre este campo.

É importante frisar ainda uma preocupação das autoras Abramowicz e Oliveira (2010), que apontam que a maior parte dos estudos é realizada dentro dos espaços escolares e perguntamse em outros espaços existe cultura infantil.

Interessante notar que a maior parte dos estudos feitos sobre as culturas infantis foi realizada em contextos escolares, ocupados predominantemente por crianças e, por isso mesmo, locais onde os pesquisadores poderiam encontrar mais facilmente seus sujeitos de investigação. Cabe perguntar se, em outros lugares, nos dias de hoje, poderíamos encontrar as mesmas evidências da existência de uma cultura infantil autônoma? Há autores que sugerem que talvez o que estamos chamando de cultura infantil exista mais nos espaços e tempos nos quais as crianças têm algum grau de poder e controle. É o caso dos pátios da escola, no recreio, nos parques de recreação existentes nas escolas, nos tempos vagos existentes nas rotinas criadas pelos adultos, nos grupos das ruas, pois são espaços em que geralmente as crianças estão livres do olhar adulto. (ABRAMOWICZ; OLIVEIRA, 2010, p. 42)

Nesse sentido é decisivo o papel do adulto nas relações de poderes que se estabelecem dentro das instituições de educação, e na colonização das crianças e da infância, tal como apontam Qvortrup (2001) e Sarmento (2003). Ainda que essas sejam espaços onde a presença das crianças é predominante e, do mesmo modo, as culturas infantis, faz-se necessário problematizar se esses são elementos suficientes para garantir a participação e algum tipo de protagonismo das crianças.

Entender a criança como ator social, implica, portanto, em mudar a visão atual de superioridade do adulto sobre a "criança vazia". É necessário ouvir as crianças, para que os adultos possam entendê-las melhor. Compreendê-las a partir da visão delas, e não do adulto. É preciso perguntar mais, conversar mais, ver mais. É preciso estarmos atentos às crianças e suas inúmeras formas de expressar-se.

\footnotetext{
11 Essas questões foram levantadas por Tebet (2013), que retomou algumas passagens da obra de Corsaro, para afirmar que o conceito de Cultura Infantil, tal como definido pelo autor, não se aplica aos bebês. Seria possível pensarmos em outras definições para Cultura Infantil, que os abarcassem? Como ela seria? Será necessário que os bebês possam ser compreendidos como produtores de culturas infantis?
} 


\section{Referências}

ABRAMOWICZ, Anete. (Org.). Estudos da Infância no Brasil: encontros e memórias. São Carlos: Edufscar, 2015.

ABRAMOWICZ, Anete; OLIVEIRA, Fabiana de. A sociologia da infância no Brasil: uma área em construção. Revista do Centro de Educação, Santa Maria, v. 35, n. 01, p. 39-52, jan./abr. 2010.

BELLONI, Maria Luiza.Infância, mídias e educação: revisitando o conceito de socialização. Perspectiva, Florianópolis, v. 25, n. 1, 41-56, jan./jun. 2007.

CORSARO, William. Interpretative reproduction in children's role play. Childhood, v. 1, p. 64-74, 1993. CORSARO, William. A reprodução interpretativa no brincar ao "faz-de-conta" das crianças. Revista Educação, Sociedade e Culturas - Revista do Centro de Investigação e Intervenção Educativas da Faculdade de Psicologia e de Ciências da Educação da Universidade do Porto, Portugal, n. 17, 2002. Disponível em: http://www.fpce.up.pt/ciie/revistaesc/ESC17/17-5.pdf Acesso em: 15 de abril, 2018

CORSARO, William. We're friends right? Inside kids' culture. Washington: Joseph Henry Press, 2003. $249 \mathrm{p}$.

CORSARO, William. Peer culture. In: QVORTUP, Jens; CORSARO, William; HONIG, MichaelSebastian. The Palgrave handbook of childhood studies. Basingstoke: Palgrave Macmillan, 2009. p. 301- 315.

CORSARO, William. Sociologia da infância. 2. ed. Porto Alegre: Artmed, 2011.

DIP, Flavia. Sociologia da infância: o que tem sido dito sobre ela e seu impacto sobre o entendimento de protagonismo infantil e cultura de pares.2016. Trabalho de Conclusão de Curso - Universidade Estadual de Campinas, Campinas, 2016.

DURKHEIM, Émile. Educação e Sociologia. 11. ed. São Paulo: Melhoramentos, 1978.

FARIA, Ana Lúcia Goulart de. A contribuição dos parques infantis de Mário de Andrade para a construção de uma pedagogia da educação infantil, Educação \& Sociedade,v. 20, n. 69, p. 60-91, dez. 1999.

FERNANDES, Florestan. As "Trocinhas" do Bom Retiro: contribuições do estudo folclórico e sociológico da cultura e dos grupos infantis. Pro-Posições, v. 15, n. 1 (43), jan./abr. 2004.

GIDDENS, Anthony. Sociologia. 4. ed. Lisboa: FCG, 2004.

JAMES, Allison; PROUT, Alan. Constructing and reconstructing childhood: Contemporary issues in the sociological study of childhood. London and New York: Routledge Falmer, 2007 [1a ed. 1997]. 
JENKS, Chris. (Org.). The Sociology of childhood. Essential readings. Brookfield, VT: Gregg Revivals, 1982.

JENKS, Chris. Constituindo a criança. Educação, sociedade e culturas, v. 17, p. 185-216, 2002.

MARCHI, Rita de Cássia. O ofício de aluno e o ofício de criança: articulações entre a sociologia da educação e a sociologia da infância. Revista Portuguesa de Educação, Minho, v. 23, n. 1, p. 183-202, 2010.

MAUSS, Marcel. Três observações sobre a sociologia da infância. Pro-Posições, Campinas, v. 21, n. 3, p 237-244, 2010.

MOLLO-BOUVIER, Suzanne. Transformação dos modos de socialização das crianças: uma abordagem sociológica. Educação \& Sociedade, v. 26, n. 91, p. 391-403, 2005.

NASCIMENTO, Maria Letícia Barros Pedroso (Coord.). Infância e Sociologia da Infância: entre a invisibilidade e a voz. Relatório de Pesquisa. São Paulo: FEUSP, 2013.

OPIE, Iona; OPIE, Peter. (Ed.) The Oxford Dictionary of Nursery Rhymes. Oxford: OUP, 1951.

PIRES, Sergio Fernandes S.; BRANCO, Angela Uchoa. Protagonismo infantil: co-construindo significados em meio às práticas sociais. Paidéia, v. 17, n. 38, p. 311-320, 2007.

PROUT, Alan. Reconsiderando a nova Sociologia da Infância. Cadernos de Pesquisa, São Paul,v. 40, n. 141, p. 729-750, set./dez. 2010.

QUINTEIRO, Jucirema. Sobre a emergência de uma sociologia da Infância: contribuições para o debate. Perspectiva, Florianópolis: v. 20, n. Especial, p. 137-162, jul./ dez. 2002.

QVORTRUP, Jens. Nine theses about "childhood" as a social phenomenon. In: QVORTRUP, Jens. (Ed.). Childhood as a social phenomenon: lessons from an international project. EurosocialReport 47. Vienna: European Centre, 1993.

QVORTRUP, Jens. Childhood in Europe: a new field of social research12. In: CHISHOLM, Lynne et al. (Org.). Growing up in Europe - contemporary horizons. Childhood and youth studies. Berlin: Walter de Gruyter, 1995.

QVORTRUP, Jens. Childhood and societal macrostructures. In: QVORTRUP, Jens. Working Paper 9. Child and youth culture. Odense University Printing Office, 1999.

QVORTRUP, Jens. Childhood as a structural form. In: QVORTRUP, Jens; CORSARO, William; HONIG, Michael-Sebastian. The Palgrave handbook of childhood studies. London: PalgraveMacmillan, 2009.

12 Há uma versão em português desse texto disponível no site: http://cedic.iec.uminho.pt/Textos_de_Trabalho/textos/jensqvortrup.pdf 
QVORTRUP, Jens. Nove teses sobre a "infância" como fenômeno social. Pro-Posições, Campinas, v. 22, n. 1 (64), p. 199-211, jan./abr. 2011.

QVORTRUP, Jens. O trabalho escolar infantil tem valor? A colonização das crianças pelo trabalho escolar. In: CASTRO, Lúcia Rabello. Crianças e jovens na construção da cultura, v. 1, p. 129-152, 2001.

SARMENTO, Manuel Jacinto. Imaginário e culturas da infância. Cadernos de Educação, v. 12, n. 21, p. 51-69, 2003.

SARMENTO, Manuel Jacinto. As crianças: contextos e identidades. Universidade do Minho-Instituto de Educação, 1997.

SARMENTO, Manuel Jacinto. As culturas da infância nas encruzilhadas da $2^{a}$ modernidade. Crianças e miúdos: perspectivas sócio-pedagógicas da infância e educação. Porto: Asa, p. 9-34, 2004.

SILVA, Cleber Fabiano da; RAITZ, Tânia Regina; FERREIRA, Valéria Silva. Desafios da Sociologia da Infância: uma área emergente. Psicologia \& Sociedade, Itajaí, n. 21, p. 75-80, mar. 2009.

TEBET, Gabriela Guarnieri de Campos. Isto não é uma criança! Teorias e métodos para o estudo de bebês nas distintas abordagens da sociologia da infância de língua inglesa.2013. Tese (Doutorado) - Universidade Federal de São Carlos, São Carlos. 